\title{
The Conversation:
}

\section{Applying Gadamer's Theory on Seeking Understanding in a South African Context}

\section{Sharon Rudman}

\begin{abstract}
Amidst the turmoil and controversy which characterises much of the public debate on social concerns in South Africa, the issue of apartheid-type perceptions of identity continues to dictate the nature and outcome of interactions. Student feedback on a first-year English Language Studies module at Nelson Mandela University suggests that through the medium of 'hermeneutic conversations' (as described by Gadamer), there is potential to both address and overcome many of these ideologically-based obstacles which appear so persistent in our struggle for transformation. The concept of conversation forms the core of Gadamer's explanation of the quest for understanding. Gadamer describes the task of hermeneutics as establishing 'agreement, where there was none or where it had been disturbed in some way' and he claims that it is through the format of a hermeneutical conversation that such understanding is achieved. This article considers Gadamer's theory on gaining common understanding in terms of student interactions which form part of the above-mentioned first-year module. Students are prompted to enter into conversations aimed at encouraging understanding between those of diverse backgrounds. In addition, the course aims to prompt 'inner conversations' regarding everyday understanding of the world and that which is assumed as 'truth'.
\end{abstract}

Keywords: hermeneutic conversation, understanding, fusion/stretching of horizons, hermeneutic circle, language, ideology, phronesis, transformation 


\section{Introduction}

To become always capable of conversation - that is, to listen to the Other - appears to me to be the true attainment of humanity (Gadamer 2006: 358).

South African society continues to grapple with a number of issues, many of which emanate from the pre-democratic period of apartheid. As we try to engage with matters such as decolonisation and the land reform issue, the schisms in our society are highlighted by the struggle to come to shared understandings, or even interact with one another in a constructive manner. Whether explicit or implicit, the schisms based on apartheid-type divisions in our society remain one of the key factors in our misunderstanding and mistrust of one another. Reflecting on the persistence of racist ideologies and their destructive impact on our society, Makhanya (2018: webpage) writes:

All our debates are laced with racial suspicion, leading them to be unnecessarily polarised. They are riddled with myths, suppositions and disdain for fact. All this makes it impossible to have rational conversations, as evidenced by perspectives on employment, economic empowerment, transformation of sport and the current debate on land reform and land restitution.

As Makhanya reflects, racial and ethnic divisions in our society, based on stereotyped assumptions of one another, continue to dictate our experience of one another. As he notes, not only does this impact on interactions but also on the potential of successfully reaching agreements in everyday as well as larger strategic issues.

South African society is, of course, not alone in displaying race-based and ethnocentric ideologies, but is unique in the sense that such ideologies laid the basis for legislation during a forty-five year period of our history. Alexander (2002: 105) suggests that, although South Africa has entered a new political phase, identities are still constructed and perceived within the context of apartheid-type ideologies. The 'strategic essentialism' upon which the South African society was based during the apartheid years formed a racialised context in which all information was processed (Soudien 2012: 15). Soudien 


\section{Sharon Rudman}

(2012: 21) explains that these ideological structures grew to be so dominant and all-encompassing that they eventually became the 'obvious' and 'natural' way to understand things. It is the naturalisation of such essentialised notions of race in South Africa which explains why these have not only remained but also 'come to settle in the popular imagination as an entirely neutral concept' (Soudien 2012: 21). Thus the 'situation appears to be ideologically empty', rendering it 'impervious to any form of critique and deconstruction' (Soudien 2012: 15).

These ideology-based obstacles not only cause but also maintain many of the crises, contestations and conflicts in our society. The persistence of these habits of thought, disguised as 'truth', has brought to the fore the complexities involved in seeking a commonality of understanding between members of an 'apartheid-scarred' society. It is clearly not just theoretical insight which is required, but also acumen regarding the practicalities of actually living out this commonality in a day-to-day reality - not only because of the implications of this for relations and interactions with others, but also, importantly, to increase broad collective agreement in the way we understand and make sense of the world. Praeg (2014: 4) suggests that the platforms provided in higher education provide valuable opportunities for prompting critical thought which would interrogate such ideologies. Most South African students, he claims, are unaware of how their membership of particular groupings in society 'both determines and limits their perceptions of the world' and it is in the context of higher education, he proposes, that possibilities exist to address these limitations.

This article suggests that Gadamer's theory regarding 'hermeneutic' conversations can be constructively applied in the context of seeking understanding of, and with, one another in the South African context. The context of investigation will be the potential inherent in an encounter embedded within a module presented to first-year English Language Studies students at the Nelson Mandela University in Port Elizabeth. The 'encounter' is in the form of a module section on Language and Ideology and incorporates exposition, application, discussion and reflection on aspects which potentially function to perpetuate schisms in our post-apartheid South African society.

\section{Gadamer's 'Conversation'}

The concept of conversation forms the very core of Gadamer's explanation of 
the quest for understanding and is, according to him, 'the heart and soul of hermeneutics' (Wiercinski 2011b: 41). Hermeneutics refers to the process of understanding (which is primary) and interpretation (which is the explication of understanding) and functions to enable agreement and 'a proper understanding' where such does not exist - or where it has been 'disturbed' (Gadamer 2004: 292/387).

Gadamer distinguishes between a normal, everyday conversation and a 'hermeneutic' conversation (2004: 384). In the former, a common understanding of the world lays animplicit foundation for what is discussed, and these assumptions facilitate the smooth, reciprocal flow of communication. In such a conversation, a commonality of meaning is presumed and concepts are not interrogated but their meaning rather assumed. A conversation in the true hermeneutic sense, however, is initiated when understanding on a particular subject is contested (2004: 387/389) and differing perspectives need to be taken into account in coming to a mutual understanding.

\section{The Goal of a 'Hermeneutic Conversation'}

The goal of a hermeneutic conversation would be, as Gadamer (2004: 390) explains it, the 'fusion of horizons'. A 'horizon', in the physical sense, constitutes the limits of one's vision and in the same way Gadamer's metaphorical horizon points to the limits of one's ability to understand and make sense of that which one encounters. One's immediate assumption in trying to understand or interpret something, is that it will 'make sense' within the realm of meaning to which one has access, thus that it will fit into the world as one knows it.

Gadamer speaks of the process of gaining understanding as a circle (2004: 293/294) comprising an interplay between the part and the whole. The starting point would be the (mostly unconscious) particular framework within which one perceives reality, one's understanding of the world in its 'completeness' ('as a whole'). When one encounters an element which cannot be reconciled to this framework and one chooses not to ignore but to investigate this issue, a process of reflection and interaction is initiated. Dallmayr (2011: 64) describes the process as one in which the initial perception of the 'whole' is 'shipwrecked' because parts encountered 'refuse to be integrated'. This triggers an ongoing adjustment of parts and whole'. Every adjustment of one's 
horizon implies that subsequent interaction with the world is affected and now processed via the new perception of the 'whole'.

\section{The Form of a Hermeneutic Conversation}

In a hermeneutic conversation, agreement is attained, not by attempting to assume the mind of another but by trying to understand the position from which his/ her views emanate, trying to understand how what he (or she) is saying could be right (Gadamer 2004: 292). The outcome of this process is not that one sees the world exactly as someone else sees it, but that one's own horizon expands to overlap with that of another - a fusion of horizons (Gadamer 2004: 390).

The concept of understanding as a conversation is also used by Gadamer to describe the inner thought process which facilitates the attempt to make sense of matters for oneself (Gadamer 2004: 422). He explains that:

Because our understanding does not comprehend what it knows in one single inclusive glance, it must always draw what it thinks out of itself, and present it to itself as if in an inner dialogue with itself. In this sense all thought is speaking to oneself.

Gadamer's words imply that sometimes we can sense knowledge or perhaps even know things in an unconscious form - but this does not mean we understand them. In order to understand, we need to draw out that 'knowing' - unravel it - by trying to explain it to ourselves. Gadamer's view is of 'the conversation with oneself as an inner dialogue of the soul seeking understanding [as] an infinite dialogue' (Wiercinski 2011a: 17).

\section{Embarking on a Hermeneutic Conversation}

As previously mentioned, Gadamer (2004: 295) describes the role of hermeneutics as clarifying 'the conditions in which understanding takes place'. As such, he suggests that certain conditions will increase the potential for success in such a process.

Firstly, a conversation should be approached in an appropriate spirit, with participants jointly committed to the goal of reaching an understanding 
(2004: 388). The purpose of such a conversation should be explicitly understood as the attainment of a commonality of understanding rather than the attempt to debate or convince one another (Gadamer 2004: 389).

Secondly, Gadamer emphasises the value of understanding that, as an inevitable consequence of 'belonging' to a specific society or community', we all inherit prejudices and are thus, whether implicitly or explicitly, moulded by them. A consequence of one's inevitable ideological bias is that one most likely has (albeit unconscious) preconceptions and assumptions regarding the particular subject at hand in a conversation (Gadamer 2004: 271). Gadamer refers to Heidegger's description of such assumptions as 'imperceptible habits of thought' - as opposed to authentic knowledge (Heidegger 1962: 153). However, through making explicit our ideological assumptions and acknowledging them as constitutive of our present horizon, we are able to enter the hermeneutic circle and test the validity of such prejudices through interaction with new aspects of the world which we encounter (Bernstein 1982: 828). The quest for true understanding should thus be focused on 'the thing itself', rather than influenced by our 'habits of thought' or related projections (Gadamer 2004: 270).

A third aspect to note is the role of language as a medium for a hermeneutic conversation. Language is the medium in which communication and explanation happen and the context in which potential agreement can be reached. In embarking upon a hermeneutic conversation aimed at interpretation of meaning and understanding, commonalities of signification should not be taken for granted, particularly where contextual differences (for example cultural or temporal) exist. In a hermeneutic conversation, where understanding and agreement are consciously sought rather than assumed, 'language as the medium of understanding must be consciously created by an explicit mediation' (Gadamer 2004: 386).

It is worth noting that beyond accommodating agreement and commonality of comprehension, Gadamer (2004: 399) also accedes that language has the potential of initiating relationships:

Thanks to the verbal nature of all interpretation, every interpretation includes the possibility of a relationship with others. There can be no speaking that does not bind the speaker and the person spoken to.

Gadamer suggests that this process of coming to an agreement (even if it is the 


\section{Sharon Rudman}

proverbial 'agreement to differ', one might add), holds the inherent possibility of initiating a bond between participants - no matter that the initial perception of one another may be as 'alien' or 'other'.

Finally, Gadamer warns that because every conversation has 'a spirit of its own', it is futile to try to control the outcome of such a linguistic interaction (2004: 384). In discussing Gadamer's theory of conversation, Wiercinski (2011a: 17/21/22) cautions against assessing an 'awkward' or 'difficult' dialogue as problematic. The readiness to share and discuss diverse views may very well lead to confrontation, but this need not be seen as counterproductive, as long as participants persist in the quest for a common understanding. In fact, it is often the 'psychologically difficult dynamics' in such a conversation that contribute vitality and creativity to the interaction (Wiercinski 2011a: 17). It is, of course, important in such a situation for participants to consciously persist in the application of empathy and the resolve to 'treasure the otherness of the other' (Wiercinski 2011a: 20). However, even if, at the end of the conversation, an issue remains unresolved, the interaction remains a tangible reminder of 'the intrinsic power of speaking and the power of listening'. For this reason, a controversy which is not resolved should not be perceived as a failure. Even in such a case, the question and answer structure of a dialogue 'leads to liberation from the personal goals toward a new communion with the partner and an enriched understanding of the matter in question' (Wiercinski 2011a: 7).

\section{Phronesis: The Goal of 'Understanding'}

Gadamer (2004: 823) claims that whilst understanding certainly requires interpretation, an essential part of it is 'application'. In this respect, he employs the term 'phronesis' as used by Aristotle in referring to 'practical knowing or practical reasoning, for human living' (Johnson 2012: 145) or as 'moral knowledge' (Duvenage 2015: 78). This kind of understanding involves a synthesis of knowledge and virtue, of understanding and application particularly as it relates to the manner in which we live side-by-side with others in the world. He (Gadamer 1975: 288) explains that phronesis:

... appears in the fact of concern, not about myself, but about the other person. Thus it is a mode of moral judgement ... The question here, 
then, is not of a general kind of knowledge, but of its specification at a particular moment .... The person with understanding does not know and judge as one who stands apart and unaffected; but rather, as one united by a specific bond with the other, he thinks with the other and undergoes the situation with him.

This kind of knowledge is thus not an 'objective', detached form of reasoning but rather the act of applying understanding to a specific human context in which one's focus is the good of the other (Duvenage 2015: 80).

It is through the appropriate interrogation of our own ideas, as well as those of others, that the potential lies for working towards an agreement in terms of understanding. Furthermore, it is through this process - as we encounter and learn about one another - that we gain insight into the most suitable way in which to apply this understanding. As Gadamer often points out, understanding is not a one-time event, nor is it simply a destination; it is, instead, a journey which constantly unfolds, a journey which is, as much as any conclusions reached, a part of the process of gaining this understanding. Gaining phronesis or 'practical wisdom' is a major aspect of this process.

\section{The Academic Context: English Language Studies 111}

Encounters between students in a first-year English Language Studies module at NMU appear to reflect much of what is described by Gadamer as a 'hermeneutic conversation'. In addition, individual student reflections imply that such 'conversations' were not limited to the literal interpersonal interactions but also prompted 'inner dialogues' in an attempt to make sense of what was encountered. In an attempt to better understand the dynamics of these events, Gadamer's theory on hermeneutic conversations has been applied to student responses.

The English Language Studies 111 (LES111) course is a semester offered in the first half of the year. The class always comprises between 450 and 700 students, most of whom have just commenced their university studies. The contact sessions for the module are made up of two double lectures per week as well as a weekly tutorial. During the first semester, four weeks are taken up by a section entitled Language and Ideology which is structured around the idea that language, as discursive interaction between human beings, 


\section{Sharon Rudman}

is reflective of ideological orientations (Belsey 1980: 45) and needs to be understood within this context. The module is coordinated and co-taught by myself and a colleague, Dr Jacqueline Luck. The assessment for this section is partly through a task which comprises three sections - one completed as a group and two as individual narratives. As lecturers, we emphasise that all parts of the task are evaluated only for relevance to the questions, and marks are not influenced by individual opinions.

The first five lectures (and accompanying tutorials) prompt students to consider the ideological nature of language by referring to, amongst others, Saussure's theory on language as a system of signs (a sign consisting of a signifier and signified), ideology as an interpretation of reality and the manner in which the latter inhabits the former as discourse. The link between discourse and common sense assumptions is discussed, with particular reference to the construction of identity. At the beginning of the sixth lecture, students hand in Part A of the task (a reflection on common sense assumptions made about different South African language groups) and commence Part B, the 'group interaction' section of the task. Groups for this section comprise five or six students with representatives of at least three different mother tongue languages among them. Each student is required to hand in a section summarising the ideas expressed by the group on a particular question. The questions relate to the ideas of 'prejudice' as presented through commonly held assumptions of the different South African language groups and how these impact on interpersonal relationships in South Africa. The marker of language, rather than race or ethnicity, is intentionally used because of the generally overwhelming political nature of the discourses surrounding the latter categories in contemporary South Africa. In addition, racial distinctions are often very closely related to those concerning language, and would thus still provide for discussion in those areas (Jansen 2013:225). Ideological assumptions related to race are mostly deeply entrenched and highly emotive and it was hoped that by approaching the issue (which is, in essence, the same) via a different route, students would be more willing to engage and perhaps risk vulnerability in engaging on this topic.

Part $\mathrm{C}$ of the task is in the form of an individual narrative and is completed after the last lecture in the section. This last section of the task requires students to write more or less a page relating to the module as a whole and whether it challenged their perceptions of their own language groups as well as those of others. The questions guiding the narrative are as follows: 
- Over the period of this module and your group discussions, have you encountered anything that challenged/ changed how you thought of the identities of,

your own language group/s and

$\circ$ other language groups?

- Has any of the content/ have any of your reflections influenced the way you think about language and the way it is used to speak about the identities of others?

This last task sums up the students' own experiences of the Language and Ideology section of the course and allows them the opportunity to reflect upon any relevant insights or opinions. As these reflections were written after the group discussions, many students used this opportunity to share their thoughts on these conversations. This section of the task has been used as data for this study because it grants insight into the students' perceptions of these interactions and highlights any 'shifts' which may have occurred throughout the module. Approximately 60 narratives were consulted in the collection of data; however, the excerpts referred to reflect themes common to the feedback as a whole. Although students are identified only by a letter of the alphabet (e.g. Student A), a grid at the end of the article reveals the home language and gender of each student.

In terms of ethical considerations, students were asked to consent (in writing) to allow excerpts of their narratives to be included in this research. The topic of research was explained to them and they were assured of anonymity if they were to consent. It was emphasised that the participation or non-participation in this study would have no impact on their assessment.

With regard to Gadamer's theory, the LES group interactions are seen as a 'conversation' in which participants (often with very different perspectives) seek clarification and understanding alongside one another. In addition, students are encouraged to dialogue not only in the conventional form with one another, but also with themselves in the form of reflection in terms of their own self-understanding (as required by Part A and Part C of the task). Through this approach, it is hoped that insight will be gained on how to better understand each other and then incorporate this understanding into everyday interactions. 
The aspects noted by Gadamer as prerequisites for a 'successful' conversation are taken into account in the preparation for these discussions. The concepts of language, ideology, discourse, common sense and identity are conceptualised in the preceding lectures in order to ensure that, during the group conversations, students will have a common frame of reference in using such terms. Of course, as Gadamer notes, the willingness of participants to engage upon a quest for commonality of understanding is essential. By explaining the manner in which meaning-making is achieved through the concepts of ideology and discourse, it is hoped that students would be persuaded, not only to interrogate their own perceptions and prejudices, but also to consider the manner in which others arrive at their own conclusions. In this sense, they are encouraged to acknowledge their own 'fore-conception of completeness' and thus understand the 'horizon' with which they start their quest for understanding. That which is addressed in the course would only relate to a very small part of a student's mindset as a 'whole' - namely only that of identity-perception as regards language usage. But it is encountering such 'parts', Gadamer claims, which prompts the activation of the hermeneutic circle and potentially then results in the revision of the 'whole'.

Although much effort is made to persuade students to enter into these conversations in an appropriate spirit, it would be unrealistic to expect that all would indeed exhibit the desired attitude. There are always those who resist any negotiation of their ideologically mediated perceptions of the world. However, the reflective feedback indicates that many, if not most, enter into these conversations with a desire to hear the 'other' and give of themselves in the negotiation of a common understanding. As the following section will show, the conversations which take place in this module (whether they be in the form of interactions or 'self-talk') appear to display numerous aspects of Gadamer's description of a 'good' conversation.

\section{Findings}

\section{Entering the Conversation with an 'Appropriate Spirit'}

Although students were aware that the module task included a section to be done as a group, they were not aware of the logistics of such until the class in which the groups were assigned. In terms of approaching the conversation with a 'good attitude', it must be said that many students express their initial 
reluctance to work in groups with those perceived as 'other'. Student A expresses his dismay at realising that he had to do the task in a group comprising members of other language groups:

Student A: My excitement was cut short when it was later said your group must consist of people that speak a different language from yours.

This student's initial apprehension at working with those he had previously considered 'other' is also reflected in the feedback of many others. But one of the themes that emerge from the narratives is the general sense of relief in encountering friendliness and acceptance from fellow group-members. Student A (from above) continues:

Student A: As I started speaking with them, I discovered what nice people they are. We connected as if we had known each other for a long time. This was a moment of realization ... The whole experience changed and challenged the way I thought about other languages and being more open-minded and [it] reminded me [that] we can all connect regardless of our groups as long as we are still human beings.

This student speaks of 'a moment of realisation', prompted by the manner in which his group members received him with warmth and immediately made him feel at home. For him this initial experience, even before the conversation had commenced, was influential in prompting him to approach the discussion with a 'good spirit'. Similarly, Student B joins his group with a sense of trepidation but is immediately reassured by the reception he receives from group members, sensing that he and his contribution will be valued:

Student B: I also felt intimidated by members of my group because I believe I regarded myself as inferior and what I say was not to be taken into consideration. As a result I concluded that I must isolate myself. But what I recognised was the friendly attitude that they gave me and I believe that I am valued by others and my contribution counts regardless of my language or race.

Because of his initial perception ('I regarded myself as inferior and what I say 
was not to be taken into consideration'), it seems likely that this student would not usually offer his opinion in a discussion. However, because of the attitude of his group members, he felt valued and thus willing to share his ideas.

\section{Foregrounding Ideological Starting Points}

A second requirement of a hermeneutic conversation, according to Gadamer, is an awareness of one's preconceptions or 'fore-knowledge' when approaching the task of understanding. Because Part A required students to explicitly note common sense assumptions regarding their own and other language groups (as well as their opinions on these), they enter into the group discussions with at least some awareness of their own ideological positions. Student $\mathrm{C}$ below speaks of an awareness of his own ideas regarding 'Afrikaners':

Student C: Sometimes we get intimidated by the way they speak or maybe by the way their body are constructed or rather the experience we have with just one of them then decide they [are] all like this. I for one am guilty of that because I thought that Afrikaners are rude, violent, racist abusers and I just thought they [are] bad people that was the common assumption I had and the identity I imposed on them, and this was all because of the apartheid. I just hated them, till I decided to zoom in.

Student $\mathrm{C}$ brings his perceptions of 'Afrikaners' to the fore and, by making such explicit, is then able to 'zoom in' and examine the validity of these in terms of his own experience. He does so in the context of his group discussion, where an encounter with an Afrikaans classmate challenges his initial ideas:

Student C: I met a sweet Afrikaner. She is the sweetest girl I have ever came across in NMU. She invited me to dinner with her family. At first I didn't want to go because I had all of this bad imaginations of how the dinner was going to be. When I got there they were so loving and caring we laughed and had a great time. It was not what I expected from Afrikaners but just the opposite of what I had in mind ... So the discussions and classes have changed the way I thought about 
Afrikaners and changed the identity I had for them, I realised that I just had a single story about them ... I have realised that in our use of language we represent a particular identity at the same time that we construct it.

Despite his reluctance to attend the supper, Student C obviously went ahead with the arrangements, resulting in a complete change of heart regarding his assumptions. In the narrative of this student one senses the initial confusion in his encounter with a 'part' which does not make sense within his 'fore-conception of completeness' - his understanding of the world ('It was not what I expected from Afrikaners but just the opposite of what I had in mind'). Gadamer claims that it is such an encounter with a 'part' that does not fit into the 'whole' that provides the potential to 'stretch' and 'reset' the limits of one's understanding of the world (one's 'horizon'). As a consequence of this experience and the resultant process of trying to make sense of it, Student $\mathrm{C}$ is prompted to reset the parameters of his understanding (or 'horizon' as Gadamer refers to it) regarding Afrikaners ("changed the way I thought about Afrikaners and changed the identity I had for them').

\section{Conversation Creates Relationship}

This narrative also reflects Gadamer's suggestion of the potential within a hermeneutic conversation for creating a sense of community between participants (Wiercinski 2011a: 22) and initiating a relationship between participants. Student $\mathrm{C}$ and his Afrikaans group mate obviously formed some sort of bond during the group discussions, resulting in his invitation to supper at her home. Not only did this particular hermeneutic conversation lead to a new understanding of the 'other' but also, it appears, a friendship previously thought impossible.

Although this is one of the more exceptional stories to emerge in the feedback, it illustrates how the act of engaging in 'real' conversation can initiate a process of reconciliation and personal transformation. The interaction provided for in the class discussions enabled the student to encounter not only the Afrikaans student, but also her whole family as fellow human beings and, based on this, prompted the realisation that relationships previously considered unthinkable are indeed possible. This proves to be a particularly touching 
illustration of Gadamer's suggestion regarding the relationships which may form through 'hermeneutic' conversations.

\section{Being Led by 'the Thing Itself'}

In becoming aware of his own prejudices, Student $C$ heightened the possibility of allowing the 'thing itself' to lead the conversation. In Student D's feedback below, one senses her group's commitment to this goal:

Student D: We had a very good time working with the English and Xhosa speaking people. We did not once say anything bad about them and there [was] peace all the time. We accepted everything they said about us or themselves good or bad. ......I realised not all isiXhosa speaking people are loud or racist. The isiXhosa speaking person did not have a bad attitude, he didn't have an attitude that said 'I don't want to be here because you are Afrikaans or English speaking people' or 'I'm here because I have to be here not because I want to be here'. the English speaking person did not think that she is better than the rest of the group because she speaks English and she also gave us a chance to give our opinions, she didn't talk alone or act like she knows everything and that she was smarter than us ...We need to talk to them to find out what their beliefs, disbeliefs and values are before we say this and that.

Student D's feedback implies that she was perhaps expecting the 'Xhosa' or 'English' people to act differently. On the contrary, she found that everyone was committed to working together towards the goal of the task, no matter that it sometimes involved saying something 'good or bad' about themselves or others. On the surface, she seems to contradict herself ('we did not once say anything bad about them ... we accepted everything they said about us or themselves good or bad') but, read in context, the first phrase appears to refer to offensive behaviour whereas the second implies the discussion of assumptions (as was required by the task). The positive attitude of group members within the discussion is reflected in her phrase: 'there [was] peace all the time'. The dialogic nature of the task is reflected in the assertion that: 'We need to talk to them to find out what their beliefs, disbeliefs and values are 
before we say this and that', reminding one that understanding is to be gained from engagement with the 'thing itself' rather than in assumptions or preconceptions of such.

\section{Defending Difficult Dialogues}

It would be safe to say that the overwhelming majority of students appear to have found the group discussions to be a positive and, for many, even groundbreaking experience. However, as one would expect, this was not necessarily an easy task to engage in and a number of students speak of feeling challenged, uncomfortable and even offended during some point of the discussions. The students below were some of those who expressed such thoughts:

Student E: I found it a challenge to actually accept some of the common assumptions that are associated with my language group.

Student F: What was challenging about the task was that some assumptions made were insulting ... assumptions made about my language are that we are rude, mean and violent meanwhile I am none of those assumptions. I am shy, quiet and I keep to myself.

The feedback of these students reflects some of the 'difficult' or awkward moments in these discussions. But, as discussed in the theory section, tension and awkwardness within a discussion are not necessarily a cause for concern. In fact, Wiercinski (2011a: 17) points out that it is often within such 'difficult' conversations that the most creative and vital interactions occur, as is intimated in the excerpt from Student G:

Student G: We couldn't settle on an answer we both approved of which for me I saw that as a challenge I had to deal with. I am Afrikaans speaking which is a long stretch to isiXhosa speaking you can imagine and because there is such a huge space between our worlds and past feud between us assumptions were made against us and that made that he shy away from Afrikaans speaking people. Certain assumptions were made about us and I struggled to argue otherwise and vice versa, therefore our communication was affected, because we both had so much to tell each other. 


\section{Sharon Rudman}

Student $\mathrm{G}$ reflects on the discussion with her isiXhosa group mate, musing that their difficult interaction could be due to different backgrounds and cultures as well as the 'past feud'. In her own words, she felt it to be 'a long stretch' from her identity to that of her group mate. Nevertheless, they engage in conversation and attempt to come to some agreement on the topic - which proves difficult ('we couldn't settle on an answer we both approved of'). As Wiercinski (2011a: 20) reminds one, a controversy which is not resolved should not be seen as a failure. Even though one is unsure whether they eventually came to a resolution in this case, she emerges from the encounter with a resolve, in Wiercinski's (2011a: 20) words, to 'treasure the otherness of the other':

Student G: I am more open minded to change and accept the fact that we are all different ... but that is the beauty of having and being part of such a diverse society that you get to explore new things everyday about language and learning from each other.

This excerpt emphasises that an awkward conversation with no obvious 'resolution' should not be seen as a failure because it still has the potential to effect within participants 'an enriched understanding of the matter in question' (Wiercinski 2011a: 7).

\section{The Role of Inner Conversations}

Gadamer suggests that the process of understanding is facilitated by both such dialogue with others as well as the 'self-talk' which characterises reflective thought, as borne out in the feedback of Student H:

Student H: In partaking in this assignment and the course in general I have been forced to look at myself critically, thus question each and every single ideology I had about a people who speak a certain language. Especially being a Sotho man in a city that's dominated by Xhosa people, it is quite challenging ergo your ideologies about a certain group are deep rooted in the fact that verbal communication is quite a hurdle. Thus you make up tales and stories in your head about the people you're observing, using the slightest indicators to construct validity within he stories you make up. This becomes your way of 
dealing with this foreign group which you've just been embedded into, you at the very least feel a sense of comfort as the foreign group becomes less and less foreign through all the tales you've created about them. As people we are afraid of what we do not understand which is why we always find ways to cope whether the basis of our coping is accurate or inaccurate we not really concerned, we 'know' what we 'know' and that becomes what we see.

In a piercingly honest manner, this student exhibits self-awareness in his assessment of his previous strategy in meaning-making. His questioning of himself regarding his own ideologies reveals his use of assumptions as a basis for understanding. He admits that, in an attempt to protect himself, he resorted to ideological assumptions in trying to make sense of the unfamiliar 'others' around him. His reasoning illustrates Gadamer's point that the quest for understanding involves a continual process of projection as one attempts to understand every new aspect which is revealed concerning the focus of one's attention. This student is very honest in revealing the dangers of imposing one's own ideological interpretation on a situation, resonating with Heidegger's warning that by doing so there is the danger of such preconceptions 'guiding' our understanding, and indeed creating a potentially misleading or downright inaccurate 'story' of its own (Heidegger 1962: 153). However, this student's readiness to admit this reveals his willingness to render himself vulnerable in order to critically examine his ideologies 'about a people who speak a certain language'. His self-talk concludes with the realisation that, as human beings, we are resistant to examining or changing that which we 'know', attributing this very aptly to an underlying fear of that which we do not understand. It appears that this student, through engaging in self-dialogue and applying concepts discussed in the module, was prompted to reason his way to an understanding of his own (previously) biased thoughts and perceptions.

\section{Stretching Horizons}

In a similar manner, Student I, an English home language speaker, tells of how the dynamics of the group engagement prompted a thought process leading to a deeper understanding of how non-mother-tongue English speakers often experience communication with her (and other English mother-tongue speakers): 
Student I: I was the only person in my language group whose home language is English. It was kind of hard to express myself in the group or to become a part of the group because I could not fit in with the different kinds of home languages. My group members could see the way I felt and there was one time that I brought the topic across that I could not understand what they were saying. They decided to negotiate their identities in order to make sure that I knew what they were talking about and for the first time ever I finally realise that people whose home language is isiXhosa or isiZulu, negotiate their identities in order to make us feel comfortable.

Although she enters the discussion with a focus on herself and her own discomfort, the student moves to view the situation from the perspective of the other. Perhaps it was the experience of feeling awkward herself which then prompted the realisation that, in order to assuage this, her group members adjusted their own approach in order to accommodate her. Although there is no indication that this 'adjustment' was explicitly discussed (except for this student bringing up her own discomfort), it seems that she noted the manner in which the group members accommodated her. The dialogic nature of the interactions, both verbal and non-verbal, and the attitude of the group members play a key role here in enabling a deeper understanding of the 'other' and how the same situation can be experienced differently by those different from oneself.

\section{Prompting Practical Knowledge}

It is understanding of this kind which appears to have the potential, not only of prompting a realisation of some sort (interpretation), but also of application indicative of the concept of 'phronesis'. Many students link their new knowledge to resolutions regarding their behaviour, for example, Student J and Student K:

Student J: This has taught me to be open-minded with people, accepting them despite their appearance or language group, because people are not always as they seem.

Student K: I'm even going the extra mile to learn Xhosa. I've learned new short sentences and I am very excited to learn more. 
Student $\mathrm{J}$ resolves to change his attitude towards others whilst Student $\mathrm{K}$ has already implemented his resolutions and started learning a new language in order to communicate better. Similarly, Student L reflects on what he has learnt about assumptions regarding his language group, and resolves to counteract these in his personal communication in future:

Student L: It had me thinking about the way I usually talk when I interact with different language groups within the university society and I decided to challenge myself to maybe just to try and talk a little bit smoother, ease down on my tone and maybe look at my body language. Maybe though my efforts it will help different language groups be comfortable around Afrikaans speaking people. I am even more keen to learn more languages and the way they do things after I had these discussions with different language groups.

Through the group discussions, this student becomes aware of how tone and body language may affect the manner in which he comes across, thus influencing the potential for effective communication. Having come to this understanding, he applies it to his own actions with the hope of eradicating such obstacles in future interactions. In this student's response one senses an illustration of Gadamer's (1975: 288) reference to phronesis as 'concern, not about myself, but about the other person' and the related resolve to 'think[s] with the other and undergo[es] the situation with him'.

\section{Paving the Way for a Common Understanding}

The group discussions allowed for interaction between students who would, it appears, normally not enter into conversation with one another regarding the sensitive but critical aspect of how they perceive one another. For many students, this appears to have been a valuable experience, resulting in a number of perceived benefits, some of which are expressed by the students below:

Student M: This module actually showed me how to live with other people from different language groups and how to accept and acknowledge other languages.

Student N: The influence that this module has had on me is that it has taught me to really evaluate the way I think. 


\section{Sharon Rudman}

Students express various ways in which they perceive themselves to have grown through doing the module (and particularly through taking part in the group discussions). For Student M, she perceives this benefit primarily in terms of her relationship with others, whereas Student N comes away with an increased sense of self-awareness and an awareness of the need to evaluate her own thought processes. Each of these aspects has emerged through a process of understanding, not only regarding the core concepts discussed in class (for example, ideology and discourse) but also insight based on the opportunity to personalise such through interaction with others as well as individual reflection. In this sense, whether in conventional form comprising interlocutors, or in metaphorical terms comprising a dialogue with oneself, Gadamer's suggestion that conversation is key to understanding appears to have been borne out.

\section{Conclusions}

Through setting up a medium for interaction between students of diverse language backgrounds, the LES module provides a forum for dialogue between students who often consider one another as 'other'. The topic of these discussions, revolving around the very sensitive issue of ideologically mediated perceptions of one another, brings pertinent, but also divisive issues to the table.

The group discussions provide the opportunity to both ask questions of the other as well as the chance to clarify potentially obscure issues. Much of the 'success' of some of these conversations could be due to Gadamer's requirements for a successful conversation having, to some degree, being met. Key linguistic concepts were clarified beforehand, 'fore-knowledge' in the form of assumptions was foregrounded and, through the lecture content, students were given insight into how a particular ideologically 'tweaked' perception of the world could influence one, thus prompting them to enter into the interactions with a sense of interest in and tolerance towards their fellow participants. In addition, the initial application of these theories (as required by Part A of the task) helped students to foreground their initial assumptions and thus be able to refer back to them, as mentioned, in their final reflections (Part C).

Gadamer (2004: 386) describes a conversation as 'a process of coming 
to an understanding'. Student feedback on the group discussions which formed part of this module implies that, for many, an increased sense of understanding was certainly gained through their participation in these. Firstly, students speak of gaining understanding regarding their own ideological positions and of an increased sense of self-awareness. The opportunity to bring assumptions about the 'other' to the table in conversation with those to whom such preconceptions related appears to be significantly effective in working through both the validity of such assumptions and in addressing the barriers set up by them. Although painful at times, the opportunity to hear the assumptions made about themselves seemed to raise important questions in the minds of students. For one, they realised that the invalidity of most of the assumptions that others made about them suggested the possible invalidity of the assumptions they make about others. In relation to this, the barriers constructed by such assumptions were shown to be largely mythical as well as destructive to both relationships and community. Finally, and most importantly, many students indicated that the realisations they had come to would influence their actions in future - here attesting to what Gadamer refers to as 'phronesis', i.e. practical wisdom or the application of knowledge. For us as South Africans, this is a particularly valuable outcome as it implies the possibility of new relationships and co-operation where these were previously thought impossible.

These dialogic encounters appear to have facilitated a 'bridging' of divisions which were based on assumptions of difference and distrust, in this way contributing to a sense of a shared understanding among students. The latter point thus refers to a 'fusion of horizons', where participants in a dialogue are able to 'stretch' their individual horizons to accommodate an overlap with that of another. There are also indications that in attaining this 'merging of horizons', many previously existing obstacles to interactions and relationships with the 'other' were removed, setting the stage for new and fruitful alliances.

Reflection on the data gained from students in this module suggests that, if approached in a manner aligned with Gadamer's principles of conversation, a dialogic encounter between those of different backgrounds and cultures may very well provide the platform necessary to achieve a better understanding of one another. Both the theory of Gadamer and the experiences of the LES students suggest that it is upon our willingness to enter into these conversations as South Africans that the vision of a reconciled and truly transformed society depends. 


\section{References}

Alexander, N. 2002. An Ordinary Country: Issues in the Transition from Apartheid to Democracy in South Africa. Pietermaritzburg: University of Natal Press.

Belsey, C. 1980. Critical Practice. New York: Routledge. https://doi.org/10.4324/9780203328439

Bernstein, R.J. 1982. From Hermeneutics to Praxis. The Review of Metaphysics $35,4: 823-845$.

Dallmayr, F. 2011. Hermeneutics and Intercultural Dialogue. In Wiercinski. A. (ed.): Gadamer's Hermeneutics and the Art of Conversation. (International Studies in Hermeneutics and Phenomenology. Volume 2.) Berlin: Lit Verlag.

Duvenage, P. 2015. Practical Wisdom (Phronesis) and Hermeneutical Politics. Phronimon 16,1:77 - 95

Gadamer, H-G. 2004. Truth and Method. Weinsheimer, J. \& D. Marshall (trans.). $2^{\text {nd }}$ Edition. New York: Continuum.

Gadamer, H-G. [1972] 2006. The Incapacity for Conversation. Vessey, D. \& C. Blauwkamp (trans.). Continental Philosophy Review 39,4:351 - 359. Gadamer, H-G. 1975. Truth and Method. New York: The Seabury Press. Heidegger, M. 1962. Being and Time. Macquarrie, J. \& E. Robinson (trans.). Oxford: Blackwell Publishers.

Jansen, J. 2013. We Need to Act. Johannesburg: Bookstorm and McMillan. Johnson, P.A. 2012. The Enigma of Practical Reasoning. In Portocarrero, M., L. Umbelino \& A. Wiercinski (eds.): Hermeneutic Rationality. International Studies in Hermeneutics and Phenomenology. Volume 3. Berlin: Lit Verlag.

Makhanya, M. 2018. Dear IRR, Racism is Real. News24. (25 March 2018). Available at:

https://www.news24.com/Columnists/Mondli-Makhanya/dear-irrracism-is-real-20180323 (Accessed on 26 March 2018.)

Praeg, L. 2014. A Report on Ubuntu. Pietermaritzburg: University of KwaZulu Natal Press.

Soudien, C. 2012. Realising the Dream: Unlearning the Logic of Race in the South African School. Cape Town: HSRC Press.

Wiercinski, A. 2011a. The Primacy of Conversation in Philosophical Hermeneutics. In Wiercinski, A. (ed.): Gadamer's Hermeneutics and the 
Art of Conversation. (International Studies in Hermeneutics and Phenomenology. Volume 2.) Berlin: Lit Verlag.

Wiercinski, A. 2011b. 'Sprache ist Gespräch': Gadamer's Understanding of Language as Conversation. In Wiercinski, A. (ed.): Gadamer's Hermeneutics and the Art of Conversation. (International Studies in Hermeneutics and Phenomenology. Volume 2.) Berlin: Lit Verlag.

Student References

\begin{tabular}{|c|c|}
\hline $\begin{array}{c}\text { Student } \\
\text { Letter }\end{array}$ & $\begin{array}{c}\text { Home Language and } \\
\text { Gender }\end{array}$ \\
\hline A & Xhosa Male \\
\hline B & Xhosa Male \\
\hline H & Xhosa Male \\
\hline I & Afrikaans Female \\
\hline D & Xhosa Male \\
\hline C & English Female \\
\hline E & Afrikaans Female \\
\hline F & Sotho Male \\
\hline G & English Female \\
\hline J & Xhosa Male \\
\hline K & English Female \\
\hline L & Afrikaans Male \\
\hline M & Afrikaans Male \\
\hline N & Xhosa Female \\
\hline
\end{tabular}

Sharon Rudman Department of Applied Languages Nelson Mandela Metropolitan University Nelson Mandela Bay Sharon.Rudman@mandela.ac.za 